\title{
Superior Mesenteric Artery Syndrome: A Case Report with Emphasis on Radiological Findings
}

\author{
Rola Mahmood*, Ahmad Abdullah Al Naggar and Tareq Hamed Al Taei \\ Department of Radiology, Salmaniya Medical Complex, Bahrain
}

Submission: November 01, 2017; Published: November 14, 2017

*Corresponding author: Rola Mahmood, MB, BCh, BAO, Department of Radiology, Radiology Resident, Salmaniya Medical Complex, Bahrain, Email: rola.mahmood@gmail.com

\begin{abstract}
Superior mesenteric artery syndrome, AKA Wilkie's, or Cast syndrome, is a rare cause of proximal intestinal obstruction. It occurs as a result to the compression of the third portion of the duodenum by the superior mesenteric artery and the aorta. In this paper we are presenting a case of SMA of a 27 years old male who presented with abdominal pain and vomiting.
\end{abstract}

Keywords: Superior mesenteric artery syndrome; Wilkie's syndrome; Cast syndrome; Arteriomesentric duodenal compression

\section{Introduction}

Superior mesenteric artery syndrome is a rare condition first described by Rokitansky in 1861 [1-6] resulting from a reduced angle between the artery at its origin from the abdominal aorta and the transverse third part of the duodenum causing duodenal obstruction $[3,4,6]$. Symptoms are nonspecific and hence the diagnosis of the syndrome depends on high index of suspicion, supported by the radiological features of the syndrome. Treatment can either be conservative or operative, depending on the severity and cause of the condition[1,3,4-6].

Case Report

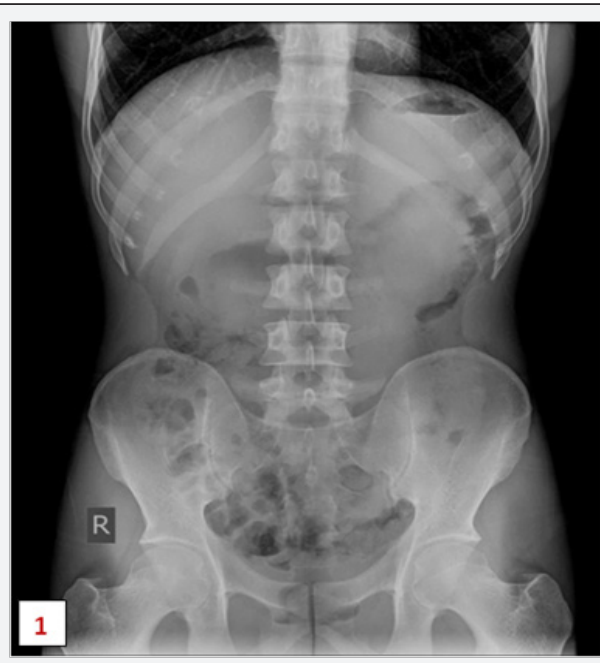

Figure 1: Unremarkable abdominal X-ray.
A 27 years old gentleman not known case of any medical illness presented with history of peri-umbilical pain, for 6 days, associated with vomiting and constipation. No history of fever or diarrhea. Unremarkable medical, allergy and surgical history. Never smoker or drinker with negative family history. On physical examination abdomen was soft and lax, no significant abnormalities were noted. Labs were unremarkable (WBC 5.78, Platelets 316, Hb 11.4) (Figure 1).

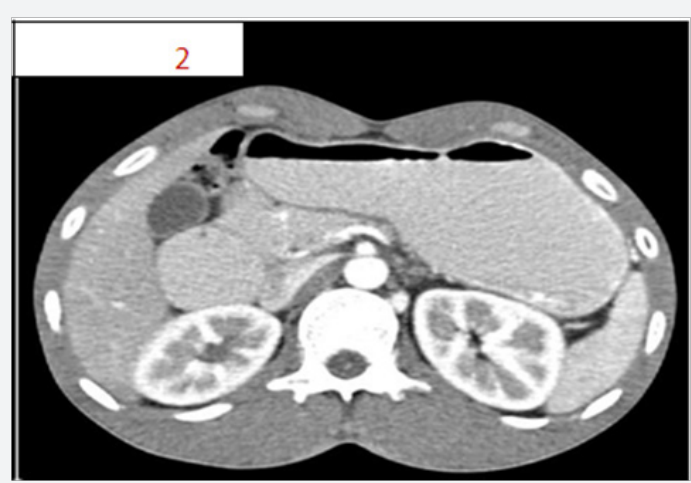

Figure 2:

Patient was admitted in the surgical ward as he was dehydrated and ill-looking. Due to the persistent vomiting NG was passed to decompress the stomach. CT abdomen with oral and IV contrast was done as the vomiting was persistent which revealed dilatation of the stomach and proximal part of the duodenum 
followed by an abrupt duodenal constriction proximal to the overlying SMA (Figure 2-7) where the aortomesenteric angle is $12^{\circ}$ (normally measure 25-60 60 $0^{\circ}$ and the aortomesenteric distance is $7.5 \mathrm{~mm}$ (normally $10-28 \mathrm{~mm}$ ) (Figure 8), CT feature consistent with superior mesenteric artery syndrome. Barium meal follow through was performed after which showed a slow flow of the contrast from the stomach through the duodenum when the patient was in supine position. Hold up within the stomach was noted (Figure 9).

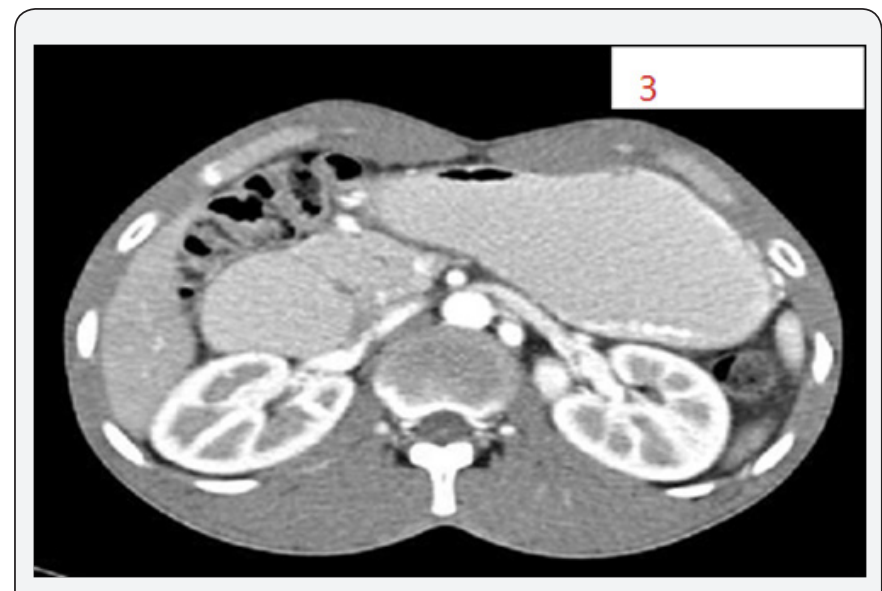

Figure 3:
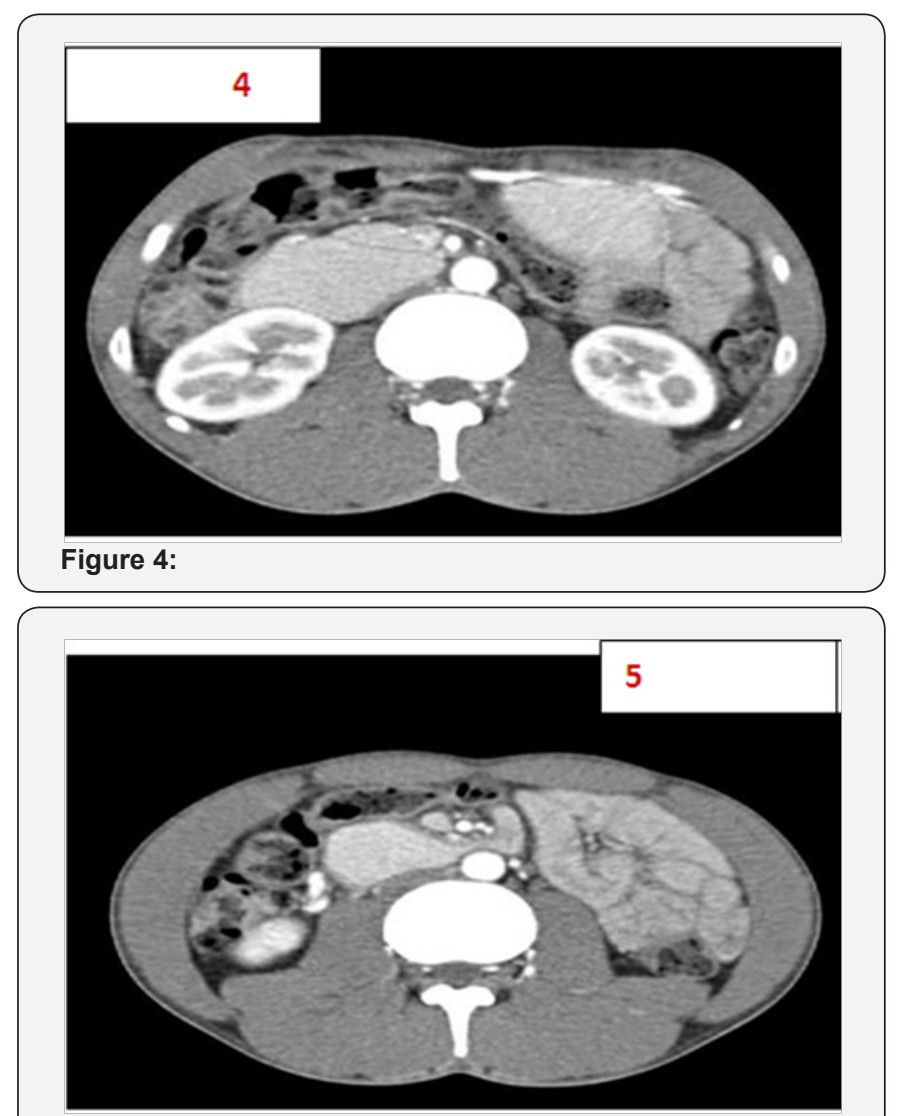

Figure 5:
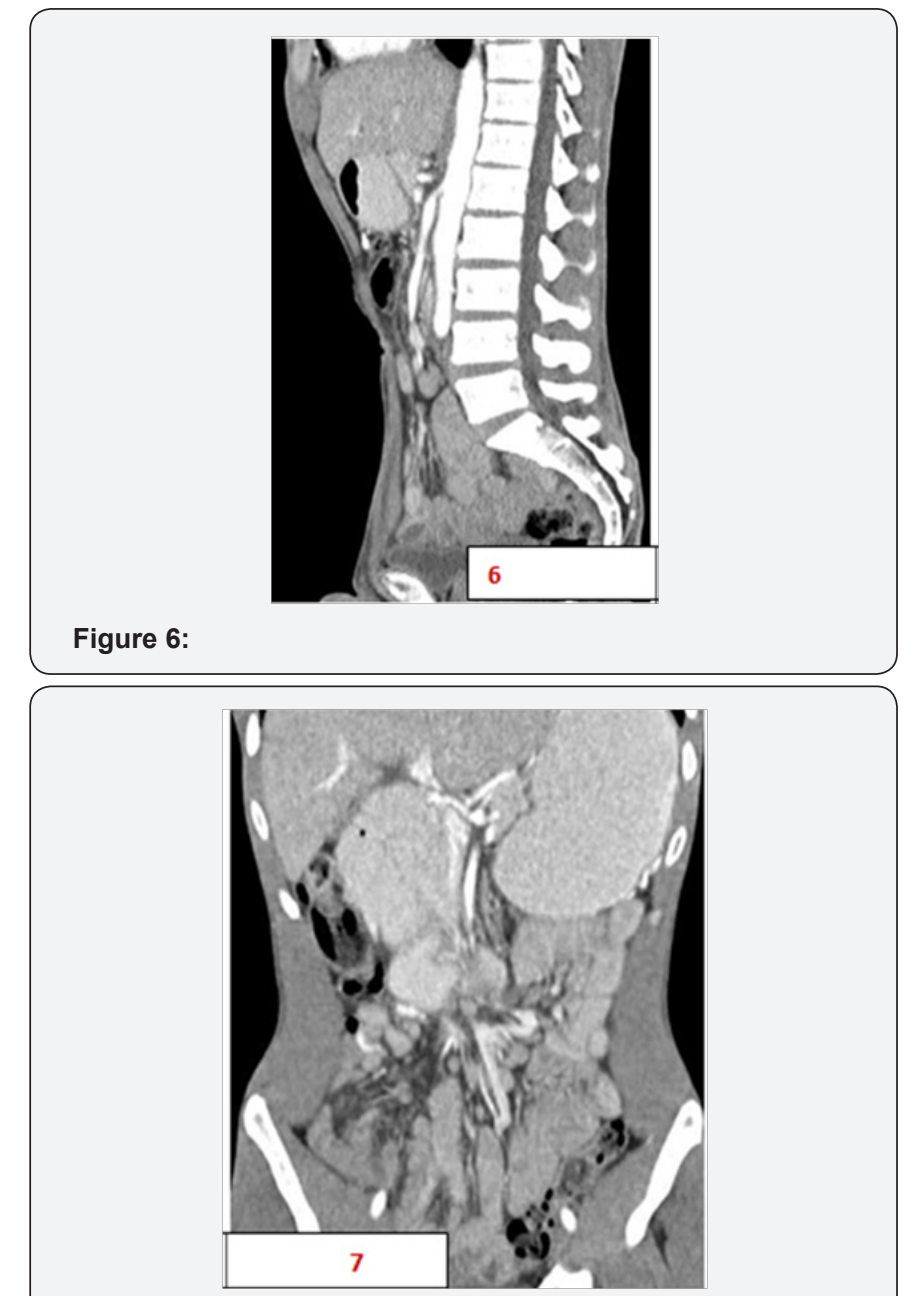

Figure 2-7: CT abdomen with oral and IV contrast showed marked dilatation of the stomach and proximal part of the duodenum followed by an abrupt duodenal constriction proximal to the overlying SMA.

When the patient was in a prone position the contrast was flowing freely to the duodenum to reach the terminal ileum (s 10-12), a consistent finding with superior mesenteric artery syndrome. During his hospital stay patient was afebrile and vitally stable, no acute events took a place. Patient was treated conservatively with NG tube and IV fluids. Patient was discharged after one week.

\section{Discussion}

Superior mesenteric artery syndrome (SMAS), also known as Wilkie's or Cast syndrome, was first described in 1861 by Rokitansky, followed by Wilkie that provided a more detailed anatomical, clinical and patho-physiologic description, naming it chronic duodenal ileus $[1,3,4,6]$. The incidence of this condition varies form $0.013-0.3 \%$. Only 400 cases have been reported so far $[1,7,8]$.

The superior mesenteric artery arises from the anterior aspect of the aorta at the level of the L1 vertebral body. It is 
enveloped in fatty and lymphatic tissue and extends in a caudal direction at an acute angle into the mesentery. In the majority of patients, the aorto-mesenteric angle and aorto-mesenteric distance is $25^{\circ}-60^{\circ}$ and 10 to $28 \mathrm{~mm}$ respectively, in which the angle correlates with body mass index [3-5]. Both parameters are reduced in SMAS, with values of $6^{\circ}$ to $15^{\circ}$ and 2 to $8 \mathrm{~mm}$ respectively, which in turn cause compression of the third portion of the duodenum $[4,5,7]$.

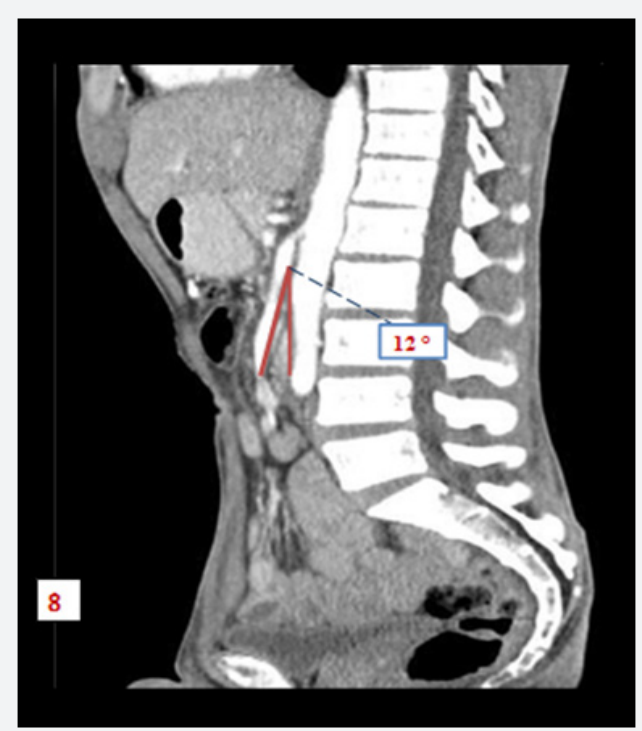

Figure 8: The aortomesenteric angle is $12^{\circ}$ (normally measure $25-60^{\circ}$ ) and the aortomesenteric distance is $7.5 \mathrm{~mm}$ (normally 10-28mm).

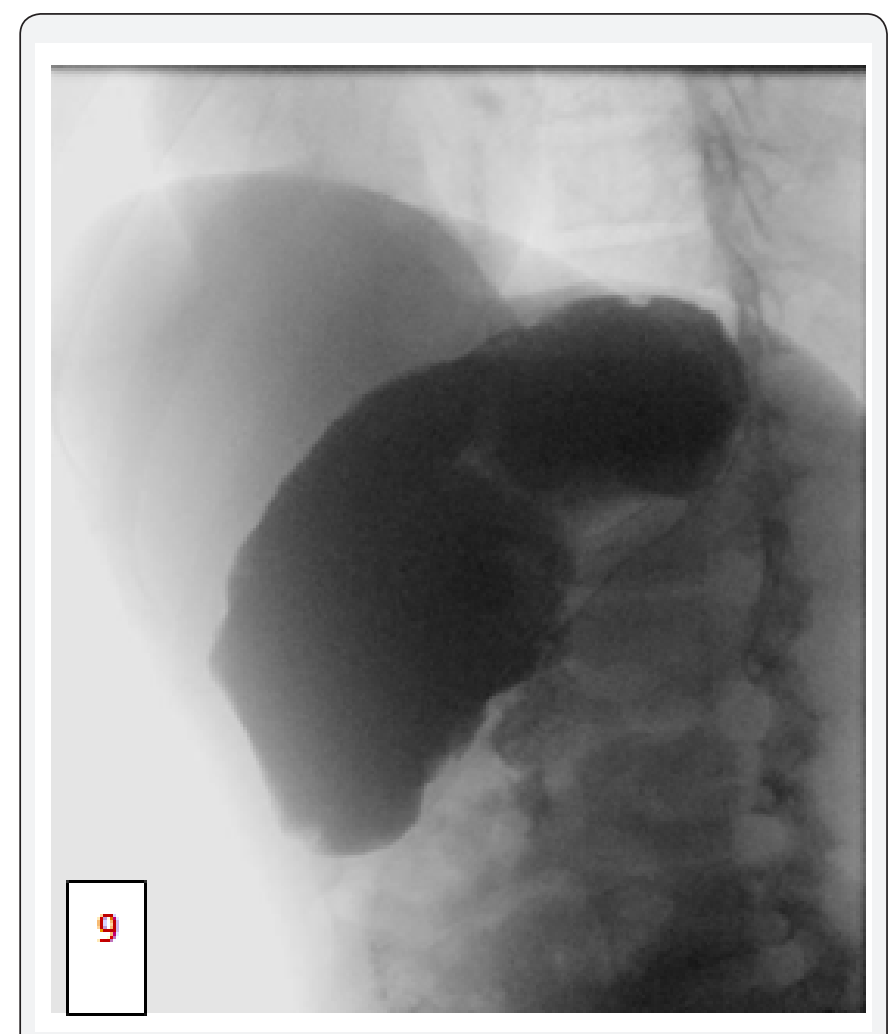

Figure 9: Barium meal follow through showing a slow flow of the contrast from the stomach through the duodenum when the patient was in supine position. Hold up within the stomach was noted.

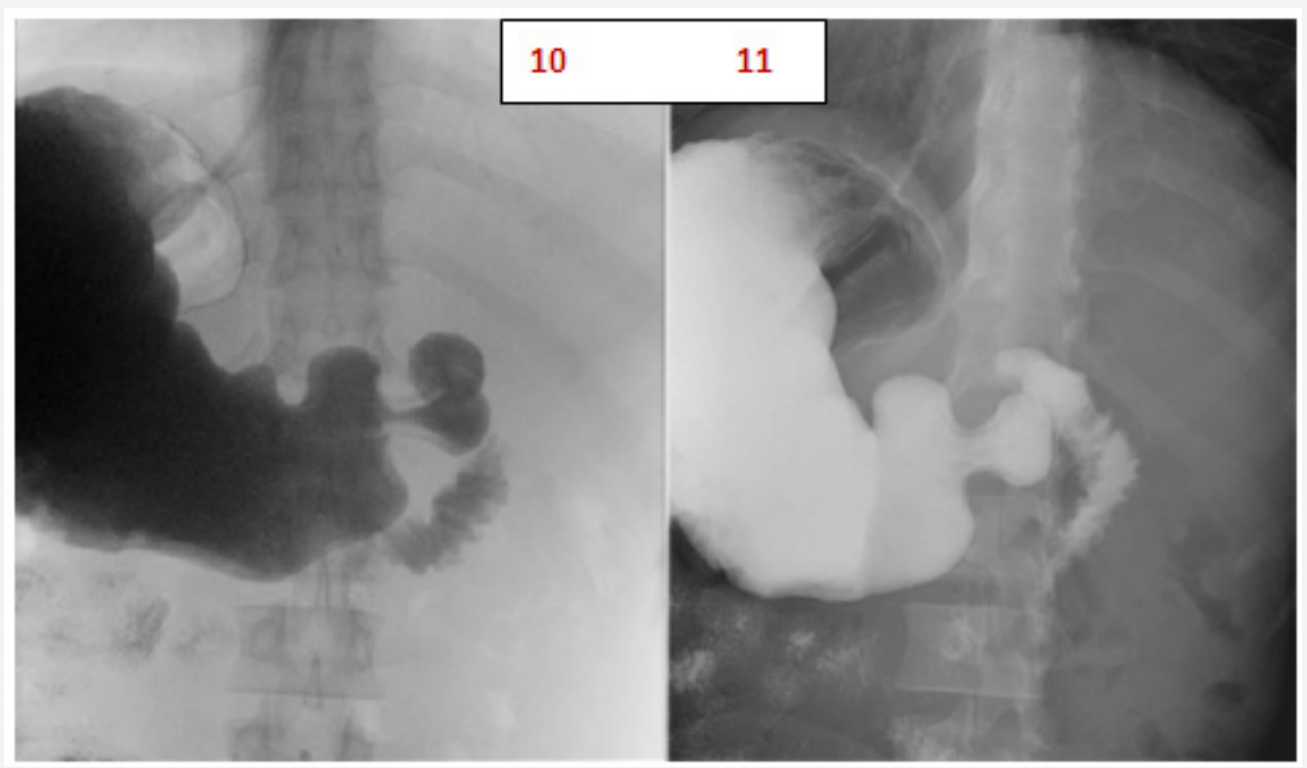

Figure 10 \& 11: Upon moving the patient to a prone position, the contrast was flowing freely to the duodenum to reach the terminal ileum.

The most common cause of SMA syndrome is severe weight loss including trauma, burns, anorexia nervosa and/or after prolonged bed rest, other causes include an abnormal high, fixed position of ligament of Treitz, unusually low origin of the SMA, a congenitally short ligament of Treitz and in rare cases following surgical correction of scoliosis, cast application abdominal aortic aneurysm and pancreatitis $[3,4,7]$. 
It mostly affects young females (10 to 39 years). The symptoms are usually chronic, comprising mostly of weight loss, bloating sensation, epigastric pain, abdominal distension, nausea and vomiting, depending merely on the cause and degree of duodenal compression. Acute presentation is uncommon $[1,7,8]$.

Diagnostic modalities include abdominal ultrasound with Doppler or contrast enhanced abdominal CT to measure the AO angle and AO distance [1,5,6]. Upper GI studies are extremely helpful in these cases, revealing the characteristic dilatation of the first and second parts of the duodenum, with an abrupt vertical or linear cutoff in the third part with normal mucosal folds. Very little barium is seen to pass into jejunum during the early part of the examination. Other finding includes delay of 4-6 hours in gastroduodenojejunal transit $[4,7,8]$.

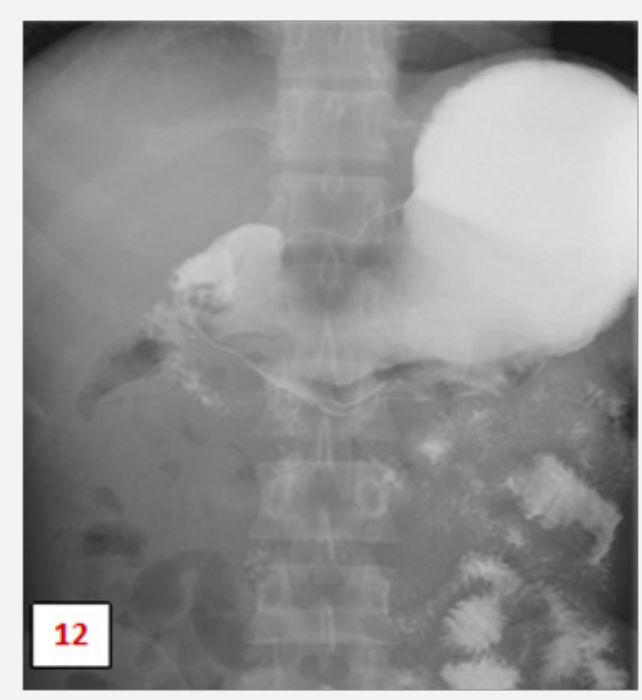

Figure 12: Contrast reaching the terminal ileum.

In literature generally, symptoms may be relieved, by lying prone, on the left lateral decubitus or knee-chest position $[1,4,5]$. Conservative initial treatment is tried at least over a period of 4 to 6 weeks and consists of correction of the electrolytes imbalance, decompression of the obstruction via a nasogastric tube and nutritional support via a nasojejunal tube placed beyond the third portion of the duodenum. However, surgical treatment (either laparoscopic or open) remains the only accepted way of managing SMAS, as conservative treatment is rarely successful $[1,5]$. The main goal is to bypass the obstruction through either a duodenojejunostomy, gastrojejunostomy or a duodenal derotation procedure ( Strong procedure). This is a popular procedure in paediatric patients, in which the third and fourth parts of the duodenum are moved into the right of the superior mesenteric artery [4,5].

\section{Conclusion}

Superior mesenteric artery syndrome is a rare condition, causing intestinal obstruction. Radiological modalities play a major role in its diagnosis and surgical methods remain the gold standard in its management.

\section{References}

1. Singal R, Sahu A, Goel M, Gupta S, Gupta M, et al. (2010) Superior mesenteric artery syndrome: A case report. N Am J Med Sci 2(8): 392394.

2. Pathak R, Shukla RC (2008) Superior mesenteric artery syndrome: case report. Nepal Med Coll J 10(2): 144-145.

3. Neto P, Paiva R, Filho A, de Queiroz FL, Noronha T (2011) Superior mesenteric artery compression syndrome - case report. J Coloproctol (Rio J) $31(4)$.

4. Mohamed A, Awami M, Bhat N, Hassan N (2008) Superior Mesenteric Artery Syndrome (SMAS); Case report and literature review. The internet journal of surgery 20(1): 1-6.

5. Zaraket V, Deeb L (2015) Wilkie's Syndrome or Superior Mesenteric Artery Syndrome: Fact or Fantasy. Case Rep Gastroenterol 9: 194-199.

6. Aziz T, Tabrez O (2016) Superior mesenteric artery syndrome: A rare case report. IJSR (2013): 6.14 5(5): 17-18.

7. Singh S, Kappal V, Kuar V, Dabar S (2014) Superior mesenteric artery syndrome presenting with acute intesntinal obstruction: A report of two cases and review of the literature, JIMSA 27(1).

8. Pivawer G, Haller J, Rabinowitz S, Zimmerman D (2004) Superior mesenteric artery syndrome and its ramifications, Science Direct 28(1): 8-10.

\begin{tabular}{l} 
Your next submission with Juniper Publishers \\
will reach you the below assets \\
- Quality Editorial service \\
- Swift Peer Review \\
- Reprints availability \\
- E-prints Service \\
- Manuscript Podcast for convenient understanding \\
- Global attainment for your research \\
- Manuscript accessibility in different formats \\
( Pdf, E-pub, Full Text, Audio) \\
- Unceasing customer service \\
Track the below URL for one-step submission \\
https://juniperpublishers.com/online-submission.php \\
\hline
\end{tabular}

